\title{
Fabric and texture at Siple Dome, Antarctica
}

\author{
C.L. DIPRINZIO, ${ }^{1}$ L.A. WILEN, ${ }^{1}$ R.B. ALLEY, ${ }^{2}$ J.J. FITZPATRICK, ${ }^{3}$ M.K. SPENCER, ${ }^{2}$ \\ A.J. GOW ${ }^{4}$ \\ ${ }^{1}$ Department of Physics and Astronomy, Ohio University, 167 Clippinger Laboratory, Athens, Ohio 45701, USA \\ E-mail: wilen@helios.phy.ohiou.edu \\ ${ }^{2}$ EMS Environment Institute and Department of Geosciences, The Pennsy/vania State University, University Park, \\ Pennsylvania 16802-7501, USA \\ ${ }^{3}$ Office of the Regional Geologist, United States Geological Survey, Denver, Colorado 80225, USA \\ ${ }^{4}$ US Army Cold Regions Research and Engineering Laboratory, 72 Lyme Road, Hanover, New Hampshire 03755-1290, USA
}

\begin{abstract}
Preferred $c$-axis orientations are present in the firn at Siple Dome, West Antarctica, and recrystallization begins as shallow as $200 \mathrm{~m}$ depth in ice below $-20^{\circ} \mathrm{C}$, based on digital analysis of $c$-axis fabrics, grain-sizes and other characteristics of 52 vertical thin sections prepared in the field from the kilometer-long Siple Dome ice core. The shallowest section analyzed, from $22 \mathrm{~m}$, shows clustering of $c$ axes toward the vertical. By $200 \mathrm{~m}$ depth, girdle fabric and other features of recrystallized ice are evident in layers (or regions), separated by layers (regions) of typically finer-grained ice lacking evidence of recrystallization. Ice from about $700-780 \mathrm{~m}$ depth, which was deposited during the last ice age, is especially fine-grained, with strongly vertical $c$ axes, but deeper ice shows much larger crystals and strong evidence of recrystallization. Azimuthal asymmetry of some $c$-axis fabrics, trends in grain-size, and other indicators reveal additional information on processes and history of ice flow at Siple Dome.
\end{abstract}

\section{INTRODUCTION}

Studies of fabric and texture are often carried out as part of the suite of measurements performed to characterize the physical properties of ice cores (Gow, 1970; Gow and Williamson, 1976; Hooke and Hudleston, 1980; Herron and Langway, 1982; Lipenkov and others, 1989; Gow and others, 1997; Thorsteinsson and others, 1997; Azuma and others, 1999, 2000; Okuyama and others, 2003). These measurements are important for understanding the physical evolution of the ice over the time-scale relevant to paleoclimatic data extracted from the core. The fabric and texture information can serve a variety of purposes, ranging from indicating the loss of stratigraphic continuity in the ice (Alley and others, 1997) to providing direct clues to climatic changes (Petit and others, 1987). The symmetry of the fabric can be related to the stress symmetry in the ice and hence may provide a measure of the ice-flow history (Alley, 1988; Thorsteinsson and others, 2003). Measurements of the fabric are also important for providing inputs to ice-flow laws (Alley, 1992; Azuma, 1994, 1995; Azuma and Goto-Azuma, 1996; Thorsteinsson and others, 1999; Ktitarev and others, 2002; Staroszczyk, 2003) as well as for testing fabric evolution models (Azuma and Higashi, 1985; Alley, 1988, 1992; Van der Veen and Whillans, 1994; Castelnau and others, 1996; Faria and others, 2002; Thorsteinsson, 2002). In this paper, we provide a detailed description of the fabric and texture at Siple Dome, Antarctica. The study is motivated generally by many of the above issues, and more specifically by recent paleoclimate data.

The Siple Dome ice core yielded interesting and unusual results from the point of view of various paleoclimate indicators. Two anomalous abrupt warming events have been recorded, at $15 \mathrm{kyr} \mathrm{BP}\left(670 \mathrm{~m}\right.$ depth, $3^{\circ} \mathrm{C}$ warming), and $22 \mathrm{kyr} B \mathrm{P}\left(722 \mathrm{~m}, 6^{\circ} \mathrm{C}\right.$ warming) (Severinghaus and others, 2003; Taylor and others, 2004). In both cases, abrupt warming seems to have been accompanied by a drop in accumulation rate, determined from gravitational fractionation of argon and nitrogen isotopes in conjunction with the stable-isotope temperature data. A dramatic drop in $\delta^{15} \mathrm{~N}$, associated with the event at $15 \mathrm{kyr} \mathrm{BP}$, can only be explained by disappearance of the diffusive layer in the firn, possibly due to the (nearly) complete disappearance of the firn itself. Analysis of the isotope fractionation data for the $22 \mathrm{kyr}$ event indicates a decrease in accumulation rate of about $70 \%$. These events are unusual because in commonly used precipitation models, warming is generally associated with an increase in saturation vapor pressure, resulting in an increase in accumulation rate. Adding to the mystery is the evidence that many impurities with important dry deposition (e.g. $\mathrm{Na}, \mathrm{Ca}$ ) are not found to change in concentration across these events as would be expected if the accumulation rate suddenly decreased.

The cause of the anomalous behavior at these two events is still largely unknown. Some possible scenarios consistent with the available data include: changes in ice-stream dynamics (possibly also affecting ice flow at the core location) or changes in the local atmospheric circulation (and hence local climate) leading to a total loss of firn, followed by normal accumulation; development of a larger convection zone; deep vertical cracks in the firn allowing ventilation; horizontal melt layers with reduced gas porosity restricting vertical fractionation.

For at least some possible scenarios, there may also be evidence embedded in the physical properties of the ice that can provide new clues to the underlying causes. Hence, as background for future interpretations of the unusual gas and chemical data, it is important to have as complete a picture as possible of the physical properties of the ice at the site. An understanding of the physical properties at Siple Dome in relation to possible paleoclimate scenarios will also be helpful in interpreting data from the proposed future West Antarctic ice sheet Western Divide core. 


\section{SITE CHARACTERISTICS}

A $1004 \mathrm{~m}$ ice core was obtained from Siple Dome during the 1996-99 field seasons. The core site is located between Kamb and Bindschadler Ice Streams at approximately $81^{\circ} 40^{\prime} \mathrm{S}, 148^{\circ} 49^{\prime} \mathrm{W}$. Reconnaissance of the region during prior seasons showed that the core site was situated on a ridge whose long direction is aligned east-west (Mayewski and others, 1995; Scambos and Nereson, 1995). The average surface temperature and accumulation rate were determined as $-25^{\circ} \mathrm{C}$ and $0.12 \mathrm{~m} \mathrm{a}^{-1}$ respectively. The core was transported to the US National Ice Core Laboratory $(\mathrm{NICL})$ in Denver, Colorado, where core processing was carried out. At that time ECM/CCM (electrical conductivity and complex conductivity) measurements (Taylor, 2003) and visual stratigraphy were performed, and samples were sent to various groups for analysis of multiple climate proxies. During the field seasons and following return to NICL, over 60 vertical thin sections were cut from the core at intervals of approximately $20 \mathrm{~m}$; all are currently archived at NICL. On three subsequent visits to NICL during the past 2 years, we imaged these thin sections with the automated fabric analysis instrument that had been installed previously at NICL. From these data we have performed a detailed analysis of the texture and fabric of the core. A description of the automated system and the method of analysis can be found elsewhere (Wilen, 2000; Hansen and Wilen, 2002; Wilen and others, 2003).

\section{RESULTS}

In what follows, we use the term recrystallization for 'migration recrystallization', which refers to the nucleation and growth of grains with new orientations at points of high stress in the ice. The new grains typically have orientations that maximize the resolved shear stress along the basal plane. For example, in ice under uniaxial compression, recrystallization results in a characteristic girdle, or multiplemaxima, pattern (Budd and Jacka, 1989; Alley, 1992). The texture of recrystallized ice is that of large interlocking grains (Duval, 1981).

To characterize the results, it is convenient to divide the core into four depth ranges as follows:

1. $0-200 \mathrm{~m}$. In this range, the fabric and texture development look 'normal'. Grains increase in size with depth in accordance with 'normal' growth (Hillert, 1965; Alley and others, 1986), and the fabric becomes progressively more concentrated toward the vertical. Interestingly, even at the shallowest depths measured $(20 \mathrm{~m})$, the fabric is not random.

2. 200-685 m. Fabric and texture indicate recrystallized ice punctuated by finer-grained regions of non-recrystallized ice. These regions can sometimes, but not always, be visualized as horizontal layers. The fabric of the recrystallized ice has the distinctive girdle pattern; however, the pattern is elongated, presumably due to the non-axisymmetric flow at the site. In the nonrecrystallized regions, the fabric is more concentrated toward the vertical than in the surrounding regions.

3. 700-780 m. No indications of recrystallization; grains are small and the fabric is highly concentrated toward the vertical.

4. 780-1003 m. Fabric and texture indicate recrystallization.
It will be useful to keep in mind the above ranges and characteristics in presenting the data. Figure 1 shows images and grain outlines of representative thin sections, with the corresponding fabric data for each displayed on a Schmidt plot. In all cases, the fabric has been rotated to horizontal, so that a grain with a vertical $c$ axis plots at the center of the Schmidt net, and a grain with a horizontal $c$ axis plots on the net perimeter. Each section in range 2 that appears to have fairly distinctly layered non-recrystallized regions is noted below the image. In many other sections, there are small clusters of finer grains that may be non-recrystallized regions, but additional targeted sampling may be needed to check this hypothesis.

Figure 2 shows a plot of grain-size vs depth. The grainsize is defined as the radius of a circle having the same area as the average area of the grains in the sample. Because many sections have very large grains that are cut off by the sample edges, a correction has been applied to account for this: grains that intersect the boundary of the analyzed region (usually the edge of the thin section) are weighted by $1 / 2$ in the grain count on the assumption that these grains are cut in half on average. The values, but not the trends, are affected by this correction. For small-grained samples this correction was unnecessary. The grain-sizes shallower than $200 \mathrm{~m}$ are consistent with theoretical predictions of normal grain growth at $-25^{\circ} \mathrm{C}$ (solid line in plot). (To model grain-sizes below $200 \mathrm{~m}$, it would be necessary to factor in the full temperature and flow history of the ice, which is uncertain.)

In interpreting the grain-size plot it is important to keep in mind the effect of the non-recrystallized finer-grained regions. These regions account for some of the noise in the data in range 2 . We have indicated on the plot (square points) those sections that clearly have non-recrystallized regions/layers. From these points, it is seen that the nonrecrystallized regions likely produce a bias (toward smaller values) on the average grain-size, and that if these sections are neglected, the grain-size increases fairly consistently with depth in ranges 1 and 2 . Initially we tried to analyze grain-sizes for the two populations of grains (recrystallized and non-recrystallized), but this turns out to be tricky because grain-size is itself a factor in this determination. An abrupt downward decrease in grain-size is observed between 685 and $700 \mathrm{~m}$, followed by a steady downward increase up to very large grains starting from about $800 \mathrm{~m}$.

Figure 3 displays the fabrics of the samples. The fabric is characterized using the eigenvalue method following Mardia (1972) and Wallenbrecher (1986). Briefly, one imagines that each $c$ axis is represented by a unit-value point mass sitting on the upper hemisphere. The moment-ofinertia tensor I for the ensemble of masses is calculated and diagonalized. The three eigenvalues $\left(\lambda_{i}\right)$ are related to the degree of concentration of $c$ axes about three orthogonal directions, given by the eigenvectors. The eigenvector corresponding to the smallest eigenvalue is defined as the concentration direction of the $c$ axes, denoted by $c_{-}$conc. To be consistent with the usual eigenvalue technique employed for fabric analysis, we use the eigenvalues $\lambda_{\mathrm{i}}^{\prime}=1-\lambda_{\mathrm{i}}$ so that the larger the value, the more concentrated the fabric. With this convention, a completely random fabric is given by $\lambda_{1}^{\prime}=\lambda_{2}^{\prime}=\lambda_{3}^{\prime}=1 / 3$, and a fabric with $c$ axes all aligned with $z$ is given by $\lambda_{1}^{\prime}=1, \lambda_{2}^{\prime}=\lambda_{3}^{\prime}=0$. The eigenvalues are defined so that $\lambda_{1}^{\prime} \geq \lambda_{2}^{\prime} \geq \lambda_{3}^{\prime}$. An elongation of the fabric is expressed by $\lambda_{2}^{\prime} \neq \lambda_{3}^{\prime}$. Care must be taken in interpreting 
eigenvalues to indicate elongated fabric since $\lambda_{2}^{\prime}$ and $\lambda_{3}^{\prime}$ will always differ by some amount due to statistical noise. The error bars for some representative sections were calculated by estimating the statistical spread in $\lambda_{2}^{\prime}$ and $\lambda_{3}^{\prime}$. The error bar for a given section was estimated by first rotating all $c$ axes so that $c_{-}$conc was along the $z$ axis (polar direction). Then, synthetic thin-section data were generated that had the same polar angles as the original section (and therefore the same value of $\lambda_{1}^{\prime}$ ), but random azimuthal angles. The error bar was taken to be twice the standard deviation in the values for $\lambda_{2}^{\prime}$ and $\lambda_{3}^{\prime}$ (taken all together) for 30 sets of these synthetic sections.

In range 1 , the fabric is mostly azimuthally symmetric (as indicated by the equality of the two smaller eigenvalues) and the fabric becomes more concentrated with depth, although the data are somewhat noisy. For one or two of the shallowest sections, there is an indication of statistically significant elongation in the fabric, but it is not consistently observed among different sections at the same or similar depths. Note also that the very shallow sections were taken from satellite cores (not Siple A core), but we lack sufficient data to decide if the variation in fabric characteristics is related to the different core sites.

In range 2, the fabric is azimuthally anisotropic as evidenced by the Schmidt plots and the difference (larger than the error bars) between the smaller eigenvalues. For ice that is apparently recrystallized with no layered regions, the fabric is an elongated girdle pattern. This is best demonstrated by looking at the combined Schmidt plot for five sections taken from the depth range $375-376 \mathrm{~m}$. Because these thin sections were taken from a continuous length of core, they have the same geographic orientation and the $c$ axis data can be combined directly. The sections in this range appear to have very few noticeable regions of finer grains. The result, shown in Figure 4, is a striking girdle pattern, having almost no $c$ axes pointing within $20^{\circ}$ of vertical. As noted, many of the sections in range 2 have regions of finer grains. For these sections, many vertical $c$ axes are superposed on the 'pure' girdle fabric. For some sections, the regions of finer grains are extremely well defined and it is possible to analyze the fabric of the finer and larger grains separately. The results of such an analysis are shown in Figure 5. For each of the samples, the fabric of the finer-grained region is more concentrated toward the vertical than the surrounding grains.

The fabric changes abruptly from one which is elongated and somewhat concentrated toward the vertical at $685 \mathrm{~m}$ to one that is azimuthally symmetric and highly concentrated at $700 \mathrm{~m}$. This change in fabric coincides with the abrupt decrease in grain-size. Over range 3, the fabric remains constant and highly concentrated.

In range 4 , the fabric develops a multiple-maxima/girdle pattern characteristic of recrystallized ice, in common with deep ice at other core sites. As the grains get very large, the statistics for determining the fabric become poor.

In Figure 6 (inset), we plot the direction of concentration of the fabric on a pole diagram similar to a Schmidt plot. Each point represents the direction of concentration of $c$ axes (c_conc) from one section as determined from the eigenvector technique. It is important to note that the azimuths of the thin sections were completely random, so the azimuth of the concentration direction is not a meaningful quantity. In Figure 6 (graph), we plot the polar angle of the concentration direction as a function of depth. The polar angle is reasonably close to zero and, to within the noise, does not appear to have changed abruptly at any particular depth.

Smaller datasets from reconnaissance studies using less accurate Rigsby-stage analyses of horizontal thin sections from the same core (Gow and Meese, 2003; Gow, http:// www.waiscores.dri.edu/Abstract01/gow01.html) are consistent with those reported here, as are results from a preliminary study using ice retrieved from Siple Dome with a hot-water drill (Gow and Engelhardt, 2000).

\section{DISCUSSION}

The fabric and texture at Siple Dome exhibit some unusual characteristics compared to other ice-core sites. The typical progression of fabric under a variety of flow conditions applicable to many polar ice cores has been summarized by Alley (1988). For simplicity, we concentrate here on ice in the upper part of ice cores situated on domes, saddle points or ridges where the stress state can often be characterized along the continuum from uniaxial compression (in the vertical $z$ direction) to uniaxial tension (along the horizontal $x$ direction). In other words, the resulting principal stress deviators can be written as:

$$
\left(\begin{array}{lll}
\varepsilon_{x} & \varepsilon_{y} & \varepsilon_{z}
\end{array}\right)=\left(\begin{array}{lll}
\frac{1}{2} & \frac{1}{2} & -1
\end{array}\right)+\alpha\left(\begin{array}{lll}
-1 & \frac{1}{2} & \frac{1}{2}
\end{array}\right),
$$

where $\alpha$ varies from 0 to 1 as the stress varies from uniaxial compression to uniaxial tension. $\alpha=1 / 2$ represents the case of pure shear.

For ice cores situated on a true dome where the dominant stress state is uniaxial compression, random shallow fabric becomes increasingly and continuously concentrated toward the vertical with depth and the pattern retains azimuthal symmetry. Grain growth is usually 'normal' (i.e. follows the normal law for growth driven by grain boundary curvature) at shallow depths and then often slows due to impurities or polygonization. The trend toward concentration of $c$ axes often accelerates (but remains continuous) at the Wisconsin/Holocene boundary coincident with a sudden decrease in crystal size, the latter generally assumed to be related to a pinning of grain boundaries from increased dust levels. Toward the bottom of a core, if the temperature increases to above $\sim-10^{\circ} \mathrm{C}$ due to the geothermal heat flux, grain-sizes increase dramatically and the fabric begins to exhibit multi-pole maxima usually associated with recrystallization. Such a scenario is exemplified by the fabric and texture at GISP2 (Gow and others, 1997) and GRIP (Thorsteinsson and others, 1997) in Greenland, and Byrd Station, Antarctica (Gow and Williamson, 1976).

When the dominant stress state is not uniaxial, the fabric and texture development is often similar to the uniaxial case, except that the fabric pattern will not be azimuthally symmetric but rather will be elongated in the direction perpendicular to the tensional axis. Taylor Dome is a good example of this case (DiPrinzio and others, 2003).

For ice cores where the dominant stress state is uniaxial tension, the fabric tightens up into a band on the Schmidt plot that represents axes lying in a plane perpendicular to the tensional axis. Vostok is a good example of this case (Lipenkov and others, 1989). At Vostok, the temperature at the lowest analyzed part of the core is $\sim-36^{\circ} \mathrm{C}$, and recrystallization is never observed to occur.

In the above descriptions, we have idealized the fabric development to some extent: The stress state is not constant as the ice flows downward, resulting in a fabric evolution 

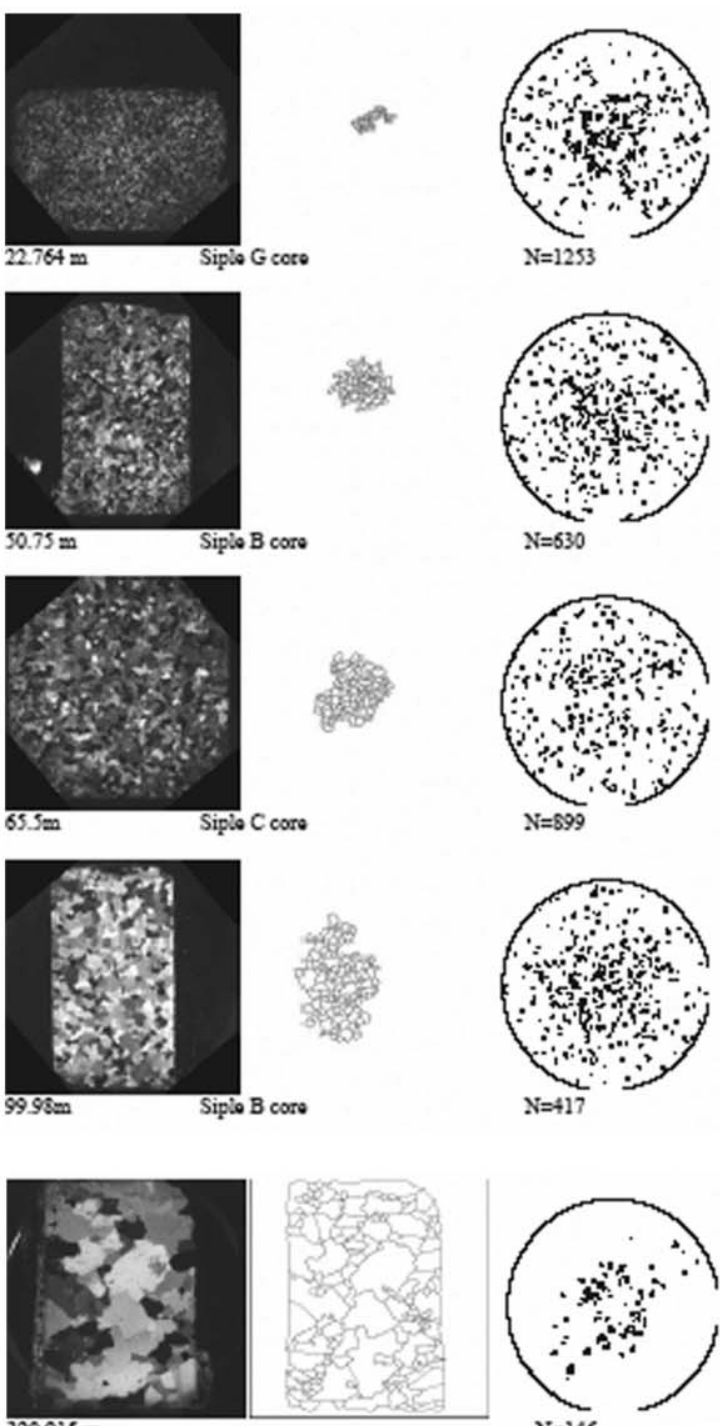

$320915 \mathrm{~m}$

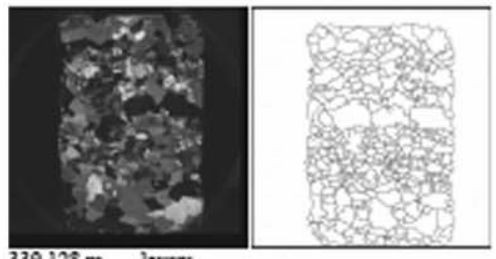

$39.128=2$ layors
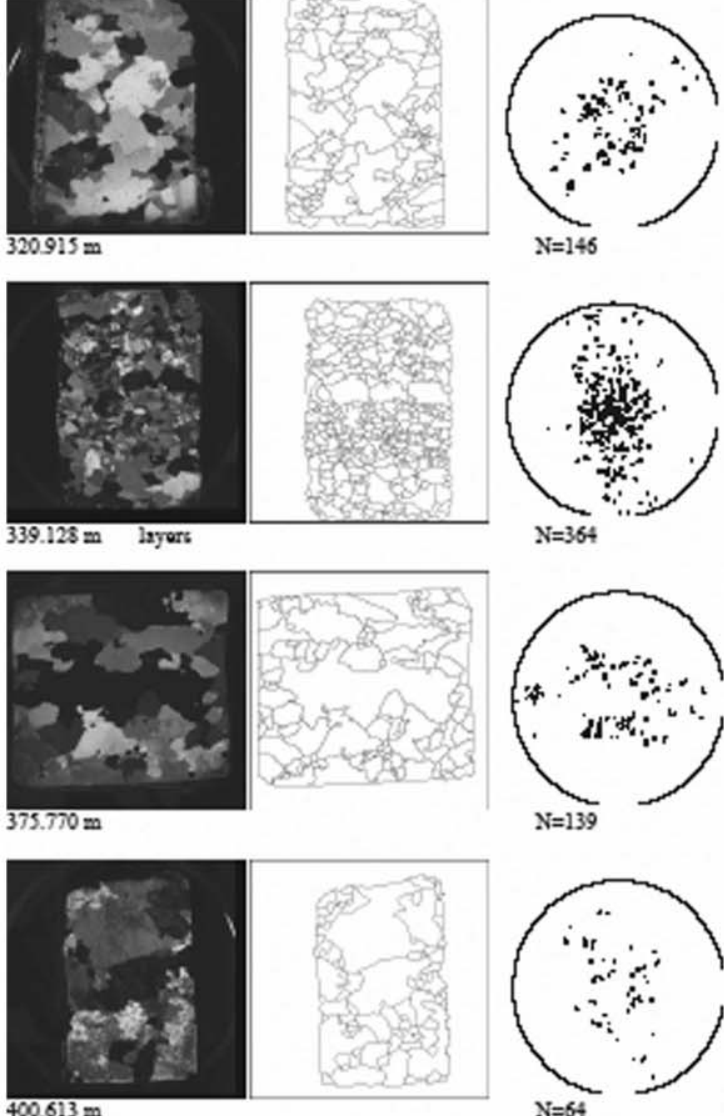

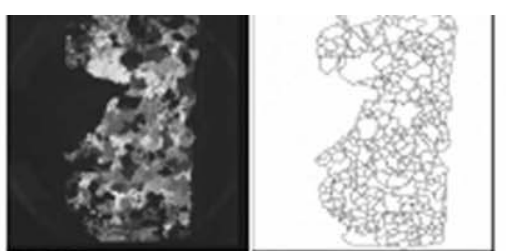

$159.435 \mathrm{~m}$

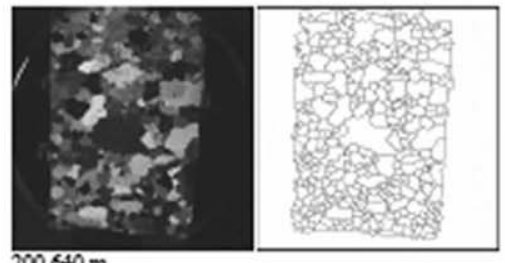

$200.640=$
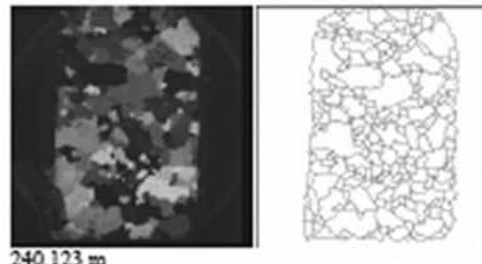

$240.123=$
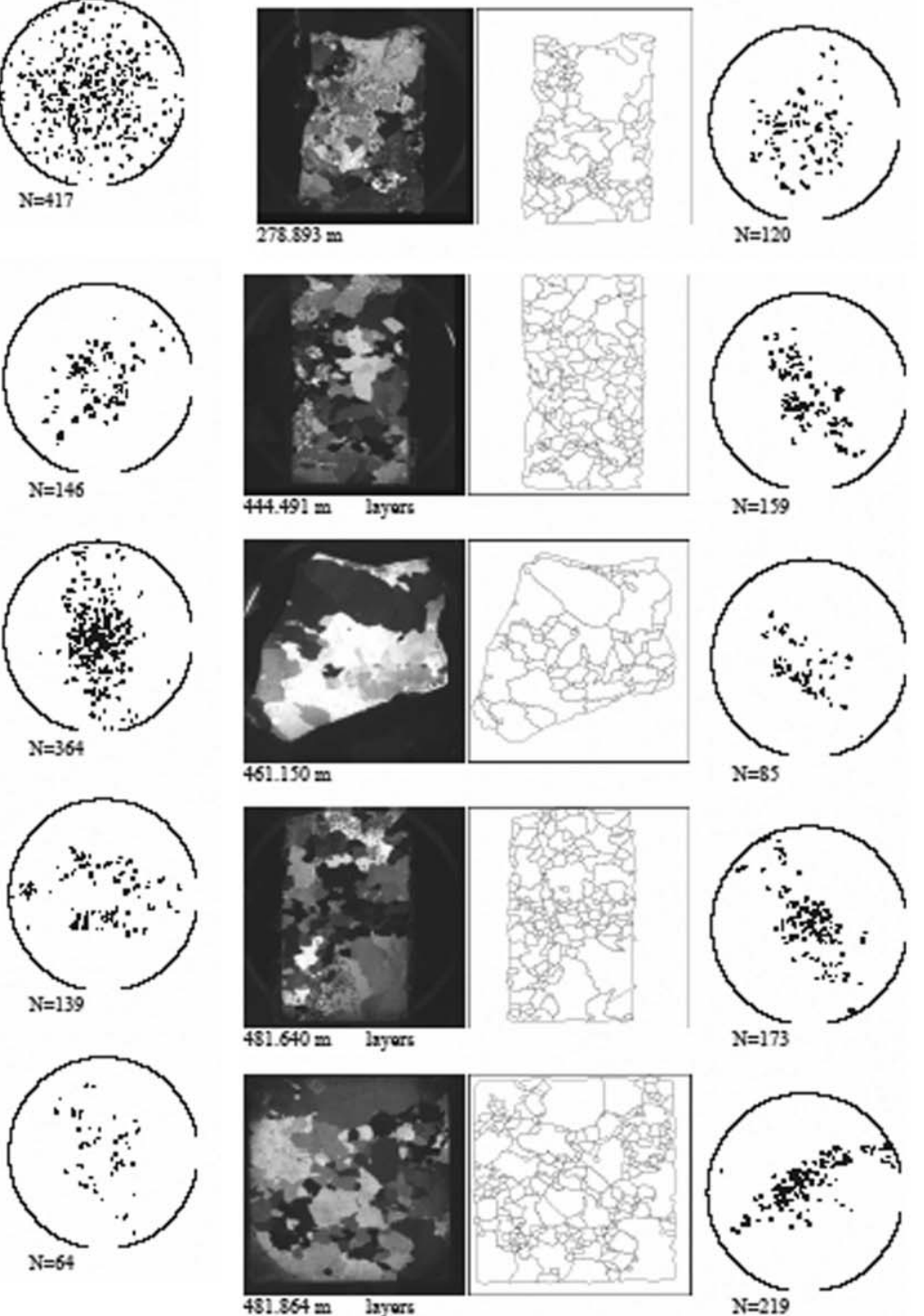

Fig. 1. Images and grain outlines of representative thin sections, with the corresponding fabric data for each displayed on a Schmidt plot. In all cases, the fabric has been rotated to horizontal. Unless noted, thin sections are from the Siple A core. The scale of the thin-section images is $10 \mathrm{~cm} \times 10 \mathrm{~cm}$. 

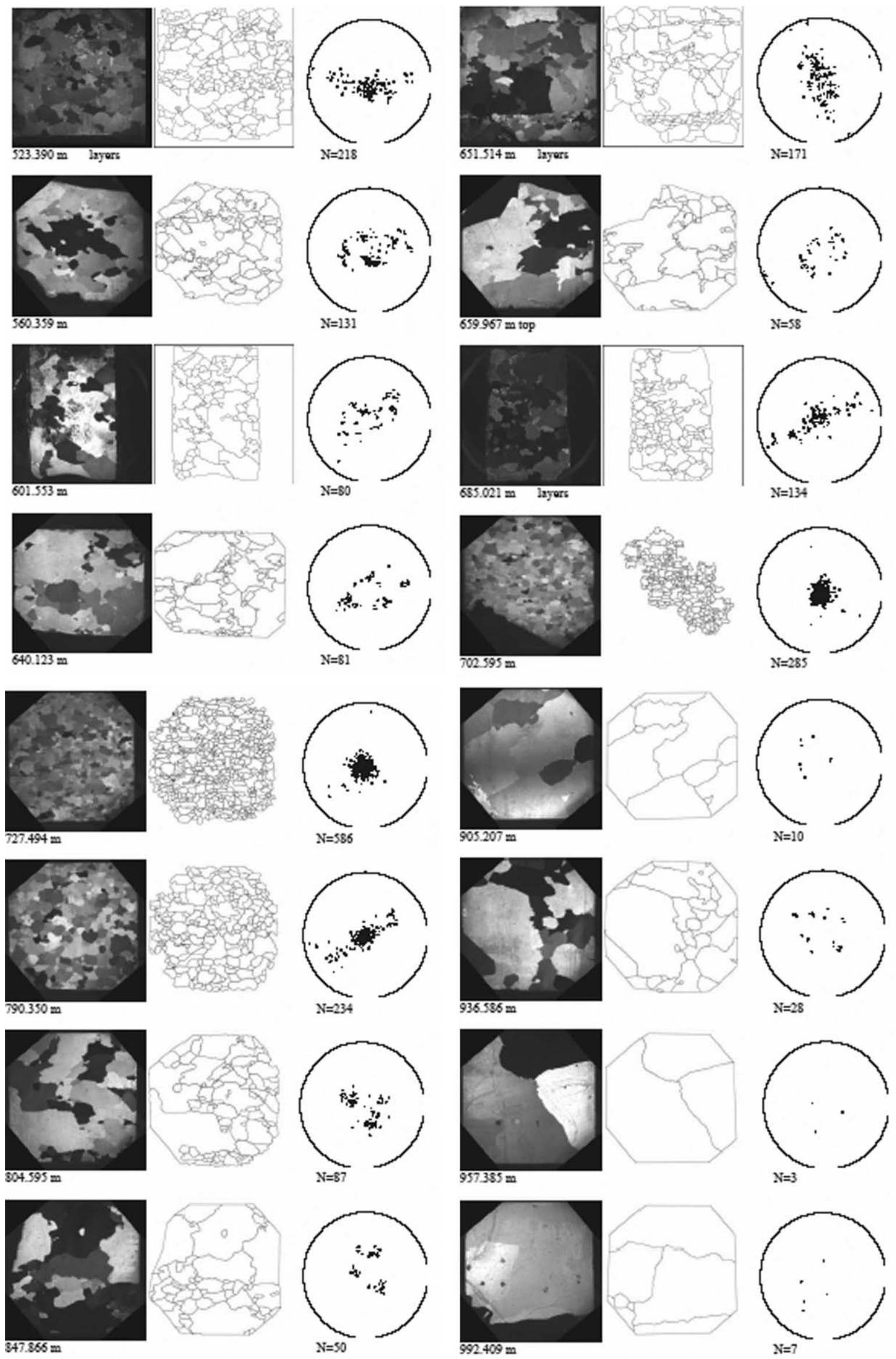

Fig. 1. (continued) 


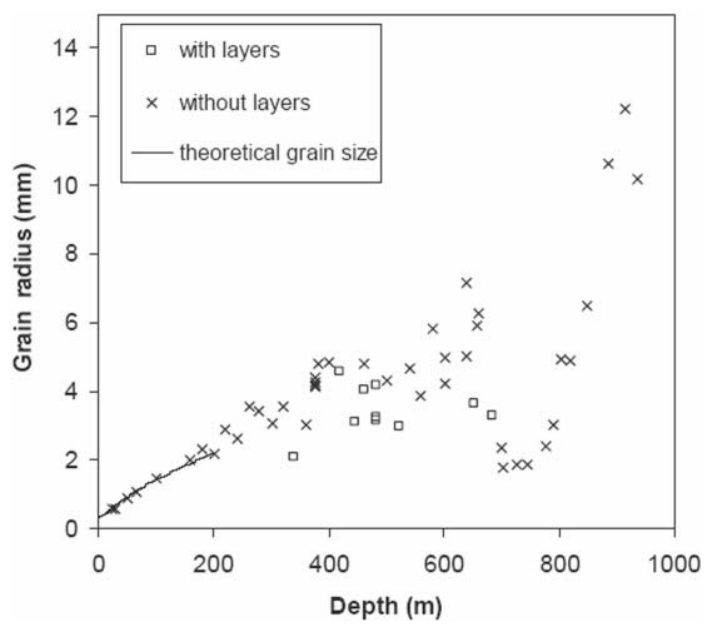

Fig. 2. Plot of grain-size vs depth. Grain-sizes for large-grained samples having many grains that are cut off by the edge of the sample have been corrected as described in the text. Squares are used for sections where non-recrystallized layers/regions are notable. Crosses are used for all other sections. The theoretical grain-growth size curve is given by normal grain growth with an initial grain radius of $0.3 \mathrm{~mm}$.

that may combine the above scenarios. Also, near the bottom of the core, simple shear becomes increasingly important. Nevertheless, the fabric development at a number of ice-core sites falls into the broad description that we have outlined.

In the context of the above description, the fabric and texture at Siple Dome can be said to be unusual in a number of respects. The principal unusual feature at Siple Dome is the appearance of fabric and texture that together seem to indicate recrystallization at shallow depths, where the temperature and total strain are still reasonably low compared to the conditions under which recrystallization is typically observed in other polar ice cores from interior dome or ridge sites. For example, at Siple Dome, at 200$600 \mathrm{~m}$ depth, the temperature varies from $-22.5^{\circ} \mathrm{C}$ to $-14^{\circ} \mathrm{C}$ (Gow and Engelhardt, 2000). In contrast, recrystallization in the Greenland cores is first observed at depths of $>2900 \mathrm{~m}$ where the temperature is $>-12.8^{\circ} \mathrm{C}$ (Gow and others, 1997).

From a theoretical point of view, this behavior is unexpected in the context of commonly held assumptions

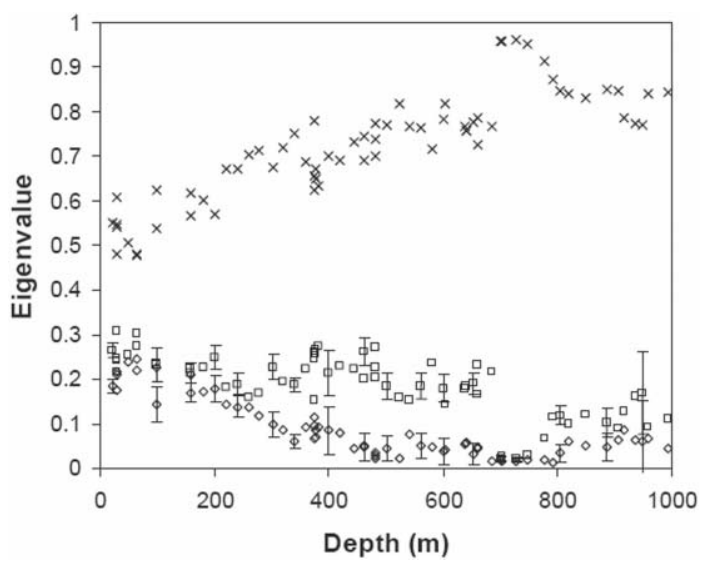

Fig. 3. Eigenvalues of the fabric plotted against depth. Crosses denote $\lambda_{1}^{\prime}$, squares denote $\lambda_{2}^{\prime}$ and diamonds denote $\lambda_{3}^{\prime}$.

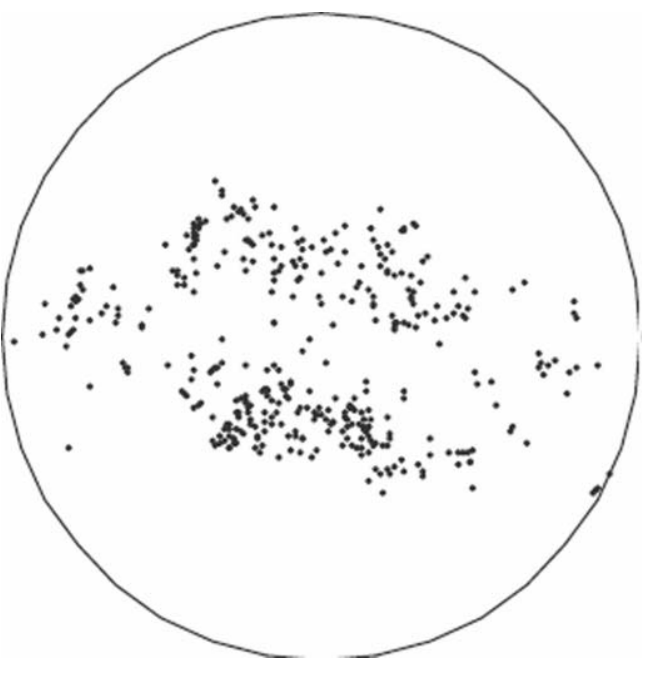

Fig. 4. Combined Schmidt plot for five azimuthally aligned sections taken from the depth range $375-376 \mathrm{~m}$. A total of 613 grains were analyzed.

about the conditions for recrystallization. Recrystallization occurs when the energy of deformation becomes large enough so that a new undeformed crystal nucleus will find it favorable to grow (Duval and others, 1983; Alley, 1992). The deformation is characterized by the density of dislocations, whose rate of formation is proportional to the strain rate. Grain growth and other processes may act to decrease the number of dislocations. Recent models of these competing effects predict the conditions under which recrystallization is expected to occur (De La Chapelle and others, 1998; Duval and others, 2000; Montagnat and Duval, 2000; Thorsteinsson, 2002; see also Alley and Anandakrishnan, in press). In many analyses, the conditions for recrystallization are generally thought to be met at temperatures $>-10^{\circ} \mathrm{C}$ and where the total integrated strain has resulted in a large dislocation density in the ice (Duval and Castelnau, 1995). Furthermore, in order for new grains to nucleate and grow, one needs many locations of high local stress. This condition is thought to be in effect after the fabric has evolved to become highly concentrated toward the vertical, causing the ice to be 'hard' with regard to further vertical compression. The conditions for temperature, strain and fabric can all be met at the bottom of the ice sheet, which is where recrystallization is often observed.

On the other hand, laboratory experiments give indirect evidence that recrystallization may occur at temperatures of $-18^{\circ} \mathrm{C}$ or even lower (Jacka, 1984). Measurements of strain vs creep were performed on initially small-grained isotropic ice, yielding curves that have a minimum in strain rate after a total strain of about $1 \%$, after which the strain rate begins to increase as the regime of tertiary creep is approached. The increase in strain rate has been attributed to the onset of (migration) recrystallization; the new grains are nucleated with orientations that allow deformation to occur by easy slip along the basal plane (Duval and others, 1983; Alley, 1992; Paterson, 1994). The regime of tertiary creep is fully developed after a total strain of approximately $10-20 \%$. In comparison, the total strain at Siple Dome at $200 \mathrm{~m}$ depth is estimated to be about $20 \%$, so it is reasonable to believe that recrystallization is active there. It should be pointed out, however, that more recent laboratory data extending measurements down to much lower stresses (and hence 

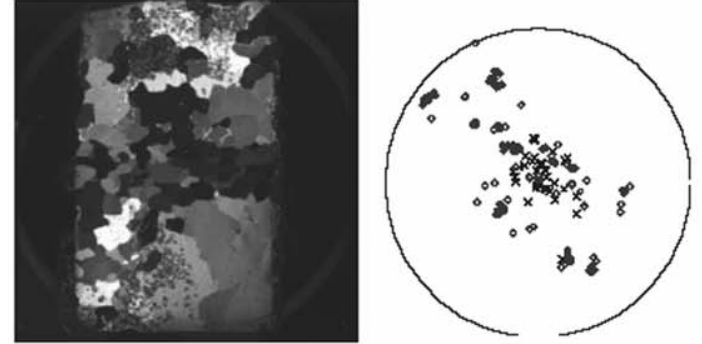

$481.640 \mathrm{~m}$
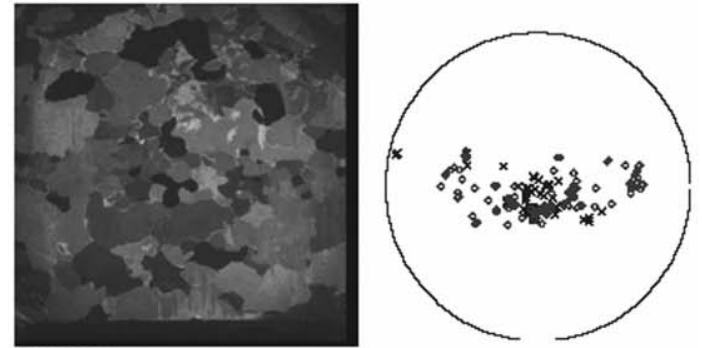

$523.390 \mathrm{~m}$
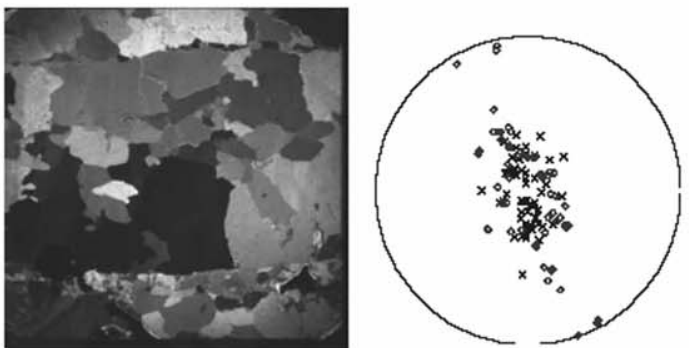

$651.514 \mathrm{~m}$
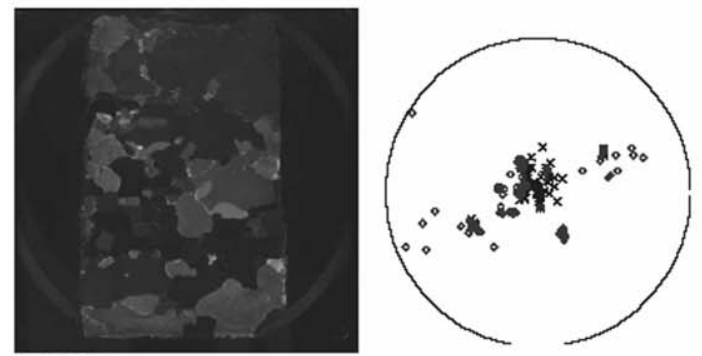

$685.021 \mathrm{~m}$

Fig. 5. Fabric of samples with distinct finer-grained layered regions. The fabric of grains in the layers is given by the crosses, and the fabric of the grains outside of the layers is given by the diamonds. The scale of the thin-section images is $10 \mathrm{~cm} \times 10 \mathrm{~cm}$.

lower strain rates) seem to indicate that at the low strain rates found in the ice sheets, recrystallization is not expected to occur for temperatures as high as $-15^{\circ} \mathrm{C}$ and likely even higher (Jacka and Li, 2000; see also Duval and others, 2000).

The lack of recrystallization at shallow depths in other ice cores may be due to a combination of factors related to temperature, strain and impurities. Ice from Greenland cores is generally dirtier than that from Antarctica, which may explain the absence of shallow recrystallization in the Greenland cores. Among inland cores from Antarctica, Siple Dome has the highest current-day annual temperatures, which may help to explain why shallow recrystallization is observed there but not at Taylor Dome or Byrd Station.

The origin of the non-recrystallized layers/regions (range 2) is not known, but is assumed to be related to some impurity or combination of impurities in the ice which may

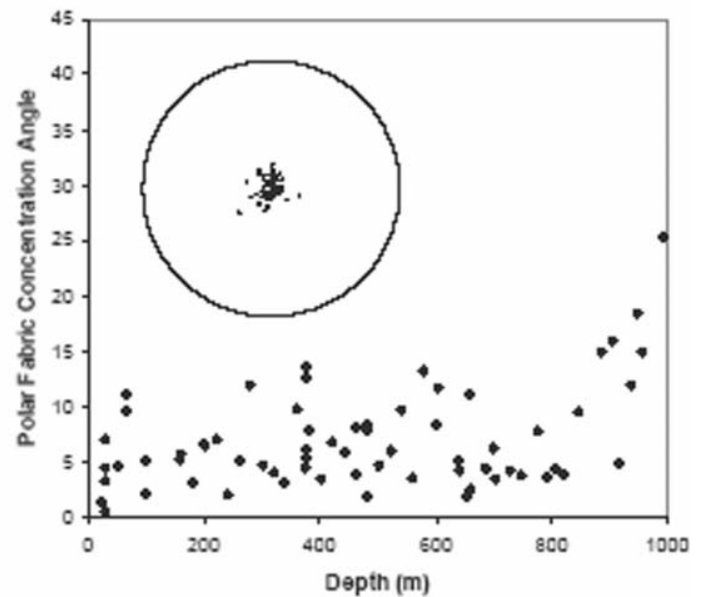

Fig. 6. Plot of the polar angle of the concentration direction as a function of depth. Inset: plot of the concentration direction of the fabric. Each point on the pseudo-Schmidt plot represents the direction of concentration of $c$ axes from one section as determined from the eigenvector technique.

pin grain boundaries, inhibiting recrystallization and grain growth. Gow and Williamson (1976) also noted similar regions of fine-grained horizontal layers associated with cloudy bands in the ice at Byrd Station. The fabric of the bands was highly concentrated to the vertical, and in some cases (for deeper ice) the surrounding crystals appeared recrystallized. Gow and Williamson (1976) attributed the layers to either regions of concentrated shearing in the ice or inhibition of recrystallization by pinning of grain boundaries. At Siple Dome, the layered regions occur at depths shallow enough that there is not likely to be much simple shear stress. Whatever the cause, it is important to keep in mind the inhomogeneities in the fabric when considering the ice rheology for flow modeling.

The only measurement at Siple Dome related to impurities that currently has high enough spatial resolution to compare to the thin-section data is ECM/CCM (Taylor, 2003). We made a preliminary attempt to ascertain if there was any correlation between distinct textural layers and the ECM/CCM signal. Figure 7 shows the results. We chose two thin sections where horizontal layering was unmistakable, and registered the ECM/CCM signal to the thin-section image. For comparison, we performed the same exercise for two thin sections that clearly had no layering. Because of various technical issues, there is a few-millimeter uncertainty in the registry between the continuously collected electrical data and the discontinuously collected thin sections. The range of depths in the ECM/CCM data spans this uncertainty. Although, in some cases, a layer seems to coincide with a jump in the signal, there are also similar jumps for the sections with no layers. Overall, our position is that no conclusion can be drawn without additional data.

If the recrystallization at shallow depths is linked to impurity-free, relatively warm ice, then this suggests a simple explanation for the abrupt change in fabric between 685 and $700 \mathrm{~m}$ as being due to an inhibition of recrystallization from the influx of higher dust levels during the last ice age, also coincident with a large amount of volcanic activity during that period (Gow, http://www.waiscores.dri.edu/ Abstract01/gow01.html). According to the current best estimate for the time-scale at Siple Dome (determined from 

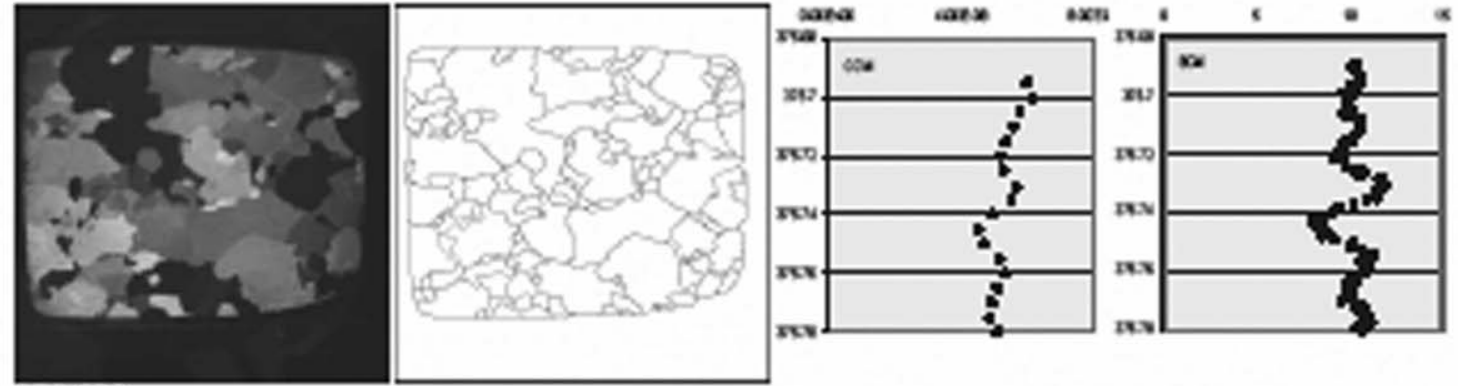

$375.680 \mathrm{~m}$
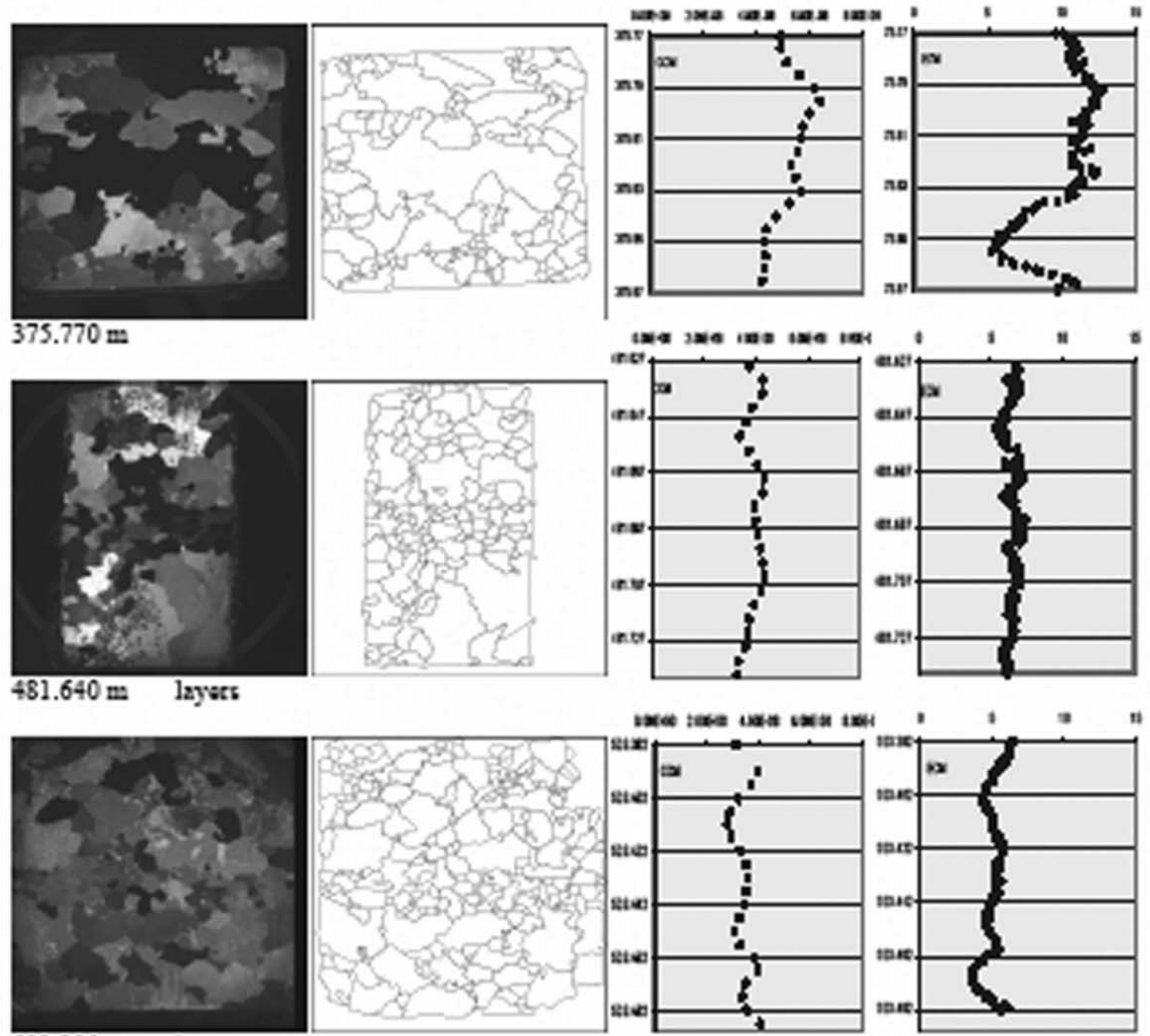

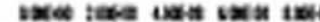

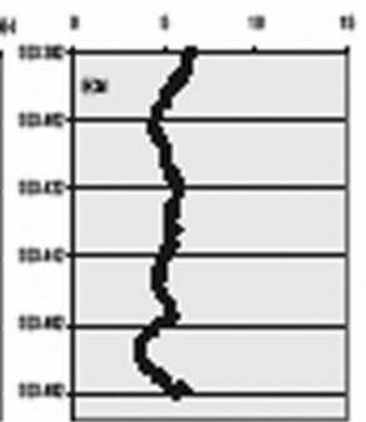

$523.390 \mathrm{~m} \quad$ layers

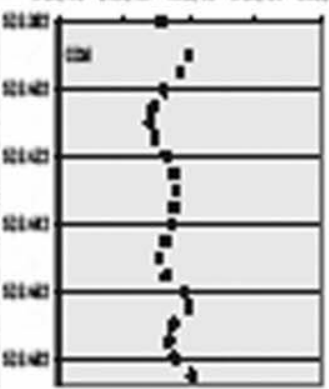

Fig. 7. Plot of the ECM/CCM data shown next to the images and grain outlines of sections without layers $(375.68 \mathrm{~m}, 375.77 \mathrm{~m})$ and sections with obvious layers $(481.640 \mathrm{~m}, 523.390 \mathrm{~m}$ ). For the plots, the vertical axis is depth in meters (with the scale matched to the adjacent section, and spanning the total depth that could correspond to the section depth range) and the horizontal axis is conductivity in $\mu \mathrm{S}$. The scale of the thin-section images is $10 \mathrm{~cm} \times 10 \mathrm{~cm}$.

methane tie points to GISP2), this depth range corresponds to $16.3-17.8 \mathrm{kyr} B$ P.

\section{CONCLUSIONS}

Understanding of the unusual features at Siple Dome is important for a number of reasons. If the shallow recrystallization is indeed anomalous and not just the fabric development expected for clean ice at these temperatures, then questions relating to the underlying causes remain. It is interesting to speculate whether some of the unusual physical features of the ice at Siple Dome might be related to the unusual features noted in the gas and chemistry data, which occur at depths that straddle the abrupt fabric and texture change. To address these questions it will be necessary to have a higher-resolution record of fabric and texture spanning the relevant depth ranges, which will be the subject of future research.

The exact mechanisms for ice deformation are still a matter of controversy (Duval and others, 2000; Montagnat and Duval, 2000). Because the flow law for ice depends on the fabric of the ice as well as physical processes that are occurring in the ice (such as recrystallization), a clear characterization and understanding of the physical properties is 
important in modeling the large-scale ice flow (Alley, 1992; Azuma, 1994; Peltier and others, 2000). These models, in turn, shed much light on the response of the polar ice sheets to past climate changes and improve our ability to predict future climate.

\section{ACKNOWLEDGEMENTS}

We thank T.K. Hinkley, G. Hargreaves, J. Rhoades and E. Cravens at the NICL for their generous help and support. We gratefully acknowledge J. Wettlaufer and Yale University for support for L. Wilen during the 2003/04 academic year. We also acknowledge Ohio University for support for C.L. DiPrinzio during 2003/04. We thank the scientific editor, J. Glen, the chief scientific editor, T.H. Jacka, as well as the reviewers, Th. Thorsteinsson and P. Duval, for many helpful comments and suggestions. We thank G. Lamorey for helpful discussions regarding registry of thin-section and electrical measurement depths and also core inclination data. This material is based partially upon work supported by the US National Science Foundation Division of Atmospheric Sciences/Earth System History and Office of Polar Programs under grants ATM 9905738, OPP 0135989, OPP 0439805, OPP 9814774, OPP 0087160, OPP 0229609, OPP 0440447, OPP 9527262 and by the G. Comer Foundation.

\section{REFERENCES}

Alley, R.B. 1988. Fabrics in polar ice sheets: development and prediction. Science, 240(4851), 493-495.

Alley, R.B. 1992. Flow-law hypotheses for ice-sheet modeling. J. Glaciol., 38(129), 245-256.

Alley, R.B. and S. Anandakrishnan. In press. The practice of glaciology. In Knight, P.G., ed. Glaciology and the Earth's changing environment. Oxford, Blackwell Publishing.

Alley, R.B., J.H. Perepezko and C.R. Bentley. 1986. Grain growth in polar ice: II. Application. J. Glaciol., 32(112), 425-433.

Alley, R.B., A.J. Gow, D.A. Meese, J.J. Fitzpatrick, E.D. Waddington and J.F. Bolzan. 1997. Grain-scale processes, folding, and stratigraphic disturbance in the GISP2 ice core. J. Geophys. Res., 102(C12), 26,819-26,830.

Azuma, N. 1994. A flow law for anisotropic ice and its application to ice sheets. Earth Planet. Sci. Lett., 128(3-4), 601-614.

Azuma, N. 1995. A flow law for anisotropic polycrystalline ice under uniaxial compressive deformation. Cold Reg. Sci. Technol., 23(2), 137-147.

Azuma, N. and K. Goto-Azuma. 1996. An anisotropic flow law for ice-sheet ice and its implications. Ann. Glaciol., 23, 202-208.

Azuma, N. and A. Higashi. 1985. Formation processes of ice fabric pattern in ice sheets. Ann. Glaciol., 6, 130-134.

Azuma, N. and 6 others. 1999. Textures and fabrics in the Dome F (Antarctica) ice core. Ann. Glaciol., 29, 163-168.

Azuma, N. and 6 others. 2000. Crystallographic analysis of the Dome Fuji ice core. In Hondoh, T., ed. Physics of ice core records. Sapporo, Hokkaido University Press, 45-61.

Budd, W.F. and T.H. Jacka. 1989. A review of ice rheology for ice sheet modelling. Cold Reg. Sci. Technol., 16(2), 107-144.

Castelnau, O., P. Duval, R. Lebensohn and G.R. Canova. 1996. Viscoplastic modeling of texture development in polycrystalline ice with a self-consistent approach: comparison with bound estimates. J. Geophys. Res., 101(B6), 13,85113,868 .

De La Chapelle, S., O. Castelnau, V. Lipenkov and P. Duval. 1998. Dynamic recrystallization and texture development in ice as revealed by the study of deep ice cores in Antarctica and Greenland. J. Geophys. Res., 103(B3), 5091-5105.

DiPrinzio, C.L., S. Hurley, L.A. Wilen, R.B. Alley, M.K. Spencer and J.J. Fitzpatrick. 2003. Study of the texture and fabric in the Taylor Dome ice core. EOS Trans. AGU, 84(46), Fall Meet. Suppl., Abstract C11C-0834.

Duval, P. 1981. Creep and fabrics of polycrystalline ice under shear and compression. J. Glaciol., 27(95), 129-140.

Duval, P. and O. Castelnau. 1995. Dynamic recrystallization of ice in polar ice sheets. Journal de Physique (Paris), IV(5), 197-205. (Supplément au 3.)

Duval, P., M.F. Ashby and I. Anderman. 1983. Rate-controlling processes in the creep of polycrystalline ice. J. Phys. Chem., 87(21), 4066-4074.

Duval, P., L. Arnaud, O. Brissaud, M. Montagnat and S. De La Chapelle. 2000. Deformation and recrystallization processes of ice from polar ice sheets. Ann. Glaciol., 30, 83-87.

Faria, S.H., D. Ktitarev and K. Hutter. 2002. Modelling evolution of anisotropy in fabric and texture of polar ice. Ann. Glaciol., 35, 545-551.

Gow, A.J. 1970. Deep core studies of the crystal structure and fabrics of Antarctic glacier ice. CRREL Res. Rep. 282.

Gow, A.J. and H. Engelhardt. 2000. Preliminary analysis of ice cores from Siple Dome, West Antarctica. In Hondoh, T., ed. Physics of ice core records. Sapporo, Hokkaido University Press, 63-82.

Gow, A.J. and Meese, D.A. 2003. Physical and structural properties of the Siple Dome ice cores. Boulder, CO, National Snow and Ice Data Centre. Digital media.

Gow, A.J. and T. Williamson. 1976. Rheological implications of the internal structure and crystal fabrics of the West Antarctic ice sheet as revealed by deep core drilling at Byrd Station. CRREL Rep. 76-35.

Gow, A.J. and 6 others. 1997. Physical and structural properties of the Greenland Ice Sheet Project 2 ice cores: a review. J. Geophys. Res., 102(C12), 26,559-26,575.

Hansen, D.P. and L.A. Wilen. 2002. Performance and applications of an automated c-axis ice-fabric analyzer. J. Glaciol., 48(160), 159-170.

Herron, S.L. and C.C. Langway, Jr. 1982. A comparison of ice fabrics and textures at Camp Century, Greenland and Byrd Station, Antarctica. Ann. Glaciol., 3, 118-124.

Hillert, M. 1965. On the theory of normal and abnormal grain growth. Acta Metall., 13, 227-238.

Hooke, R.LeB. and P.J. Hudleston. 1980. Ice fabrics in a vertical flow plane, Barnes Ice Cap, Canada. J. Glaciol., 25(92), 195-214.

Jacka, T.H. 1984. The time and strain required for development of minimum strain rates in ice. Cold Reg. Sci. Technol., 8(3), 261-268.

Jacka, T.H. and J. Li. 2000. Flow rates and crystal orientation fabrics in compression of polycrystalline ice at low temperatures and stresses. In Hondoh, T., ed. Physics of ice core records. Sapporo, Hokkaido University Press, 83-102.

Ktitarev, D., G. Gödert and K. Hutter. 2002. Cellular automaton model for recrystallization, fabric, and texture development in polar ice. J. Geophys. Res., 107(B8), 2165. (10.1029/ 2001JB000621.)

Lipenkov, V.Y., N.I. Barkov, P. Duval and P. Pimienta. 1989. Crystalline texture of the $2083 \mathrm{~m}$ ice core at Vostok Station, Antarctica. J. Glaciol., 35(121), 392-398.

Mardia, K.V. 1972. Statistics of directional data. London, Academic Press.

Mayewski, P.A., M.S. Twickler and S.I. Whitlow. 1995. The Siple Dome ice core - reconnaissance glaciochemistry. Antarct. J. US, 30(5), 85-87.

Montagnat, M. and P. Duval. 2000. Rate controlling processes in the creep of polar ice: influence of grain boundary migration associated with recrystallization. Earth Planet. Sci. Lett., 183(1-2), 179-186. 
Okuyama, J., H. Narita, T. Hondoh and R.M. Koerner. 2003. Physical properties of the P96 ice core from Penny Ice Cap, Baffin Island, Canada, and derived climatic records. J. Geophys. Res., 108(B2), 2090. (10.1029/2001JB001707.)

Paterson, W.S.B. 1994. The physics of glaciers. Third edition. Oxford, etc., Elsevier.

Peltier, W.R., D.L. Goldsby, D.L. Kohlstedt and L. Tarasov. 2000. Ice-age ice-sheet rheology: constraints from the Last Glacial Maximum form of the Laurentide ice sheet. Ann. Glaciol., 30, 163-176.

Petit, J.R., P. Duval and C. Lorius. 1987. Long-term climatic changes indicated by crystal growth in polar ice. Nature, 326(6108), 62-64.

Scambos, T.A. and N.A. Nereson. 1995. Satellite image and GPS study of the morphology of Siple Dome, Antarctica. Antarct. J. US, 30(5), 87-89.

Severinghaus, J.P., A. Grachev, B. Luz and N. Caillon. 2003. A method for precise measurement of argon 40/36 and krypton/ argon ratios in trapped air in polar ice with applications to past firn thickness and abrupt climate change in Greenland and at Siple Dome, Antarctica. Geochim. Cosmochim. Acta, 67(2), 325-343.

Staroszczyk, R. 2003. Plane ice-sheet flow with evolving and recrystallizing fabric. Ann. Glaciol., 37, 247-251.

Taylor, K.C. 2003. Siple Dome cores electrical measurement data. Boulder, CO, National Snow and Ice Data Centre. Digital media.
Taylor, K.C. and 13 others. 2004. Abrupt late glacial climate change in the Pacific sector of Antarctica. Quat. Sci. Rev., 23(1), 7-15.

Thorsteinsson, T. 2002. Fabric development with nearest-neighbour interaction and dynamic recrystallization. J. Geophys. Res., 107(B1), 2014. (10.1019/2001JB000244.)

Thorsteinsson, T., J. Kipfstuhl and H. Miller. 1997. Textures and fabrics in the GRIP ice core. J. Geophys. Res., 102(C12), 26,583-26,599.

Thorsteinsson, T., E.D. Waddington, K.C. Taylor, R.B. Alley and D.D. Blankenship. 1999. Strain-rate enhancement at Dye 3, Greenland. J. Glaciol., 45(150), 338-345.

Thorsteinsson, T., E.D. Waddington and R.C. Fletcher. 2003. Spatial and temporal scales of anisotropic effects in ice-sheet flow. Ann. Glaciol., 37, 40-48.

Van der Veen, C.J. and I.M. Whillans. 1994. Development of fabric in ice. Cold Reg. Sci. Technol., 22(2), 171-195.

Wallenbrecher, E. 1986. Tektonische und gefügeanalytische Arbeitswesen: graphische, rechnerische und statistische Verfaren. Stuttgart, Enke.

Wilen, L.A. 2000. A new technique for ice-fabric analysis. J. Glaciol., 46(152), 129-139.

Wilen, L.A., C.L. DiPrinzio, R.B. Alley and N. Azuma. 2003. Development, principles, and applications of automated ice fabric analyzers. Microsc. Res. Techn., 62(1), 2-18.

MS received 17 November 2004 and accepted in revised form 12 February 2005 